\title{
College Students' Interpersonal Relationship and Empathy Level Predict Internet Altruistic Behavior-Empathy Level and Online Social Support as Mediators
}

\author{
Ruiying Li ${ }^{1,}$, , Tao Jiang ${ }^{2}$, Jing Yong ${ }^{1}$, Hongyu Zhou ${ }^{3}$ \\ ${ }^{1}$ Institute of Psychological Research, University of International Relations, Beijing, China \\ ${ }^{2}$ Department of Psychology, Zhejiang University of Technology, Hangzhou, China \\ ${ }^{3}$ Institute of Criminology, People's Public Security University of China, Beijing, China \\ Email address: \\ ruiying_li9586@126.com (Ruiying Li),990655942@qq.com (Tao Jiang), yongjing2017@hotmail.com (Jing Yong), \\ zoma1234@163.com (Hongyu Zhou) \\ ${ }^{*}$ Corresponding author
}

\section{To cite this article:}

Ruiying Li, Tao Jiang, JingYong, Hongyu Zhou. College Students' Interpersonal Relationship and Empathy Level Predict Internet Altruistic Behavior-Empathy Level and Online Social Support as Mediators. Psychology and Behavioral Sciences. Vol. 7, No. 1, 2018, pp. 1-7. doi: 10.11648/j.pbs.20180701.11

Received: December 20, 2017; Accepted: January 15, 2018; Published: February 3, 2018

\begin{abstract}
Relationship between online and offline behavior is close. This study investigated the relationship among college students' interpersonal relationship, level of empathy, social support, and altruistic behavior in the online environment. Results: interpersonal relationship was positively correlated with empathy and online altruistic behavior, and there was a significant positive correlation between social support and online altruism. Complete mediating effect of empathy and online social support was significant. Conclusion: individual's level of empathy was the mediator of offline interpersonal relationship and online altruistic behavior; online social support was the mediator of empathy and Internet altruistic behavior.
\end{abstract}

Keywords: Internet Altruistic Behavior, Interpersonal Relationship, Empathy, Online Social Support

\section{Introduction}

Birth of Internet has led to new ways of behavior and communication [1]. Individuals can share information and exchange views with others from all over the world through Internet. Volunteers provide information, share opinions and suggestions to strangers on Internet without expecting return of the favor [2]. However, individuals' altruistic behavior requires a complex psychological process [3].

Internet altruistic behavior is the action that individuals tend to help others or society without direct purpose and expectation of social return [4]. Different from traditional environment, Internet has its unique virtual characteristics, transcending the limitation of time, space, and region. Internet altruistic behavior impacts subjective well-being [5]. From positive psychology perspective, internet environment is conducive to the arousal of adolescents' altruistic behavior in terms of moral character, emotional cognition, and self-worth [6]. Moreover, internet altruistic behavior is the typical embodiment of the positive role of internet [7]. Internet altruistic behavior provides a new valuable choice to promote morality and dedication to society. From the perspective of information dissemination, online altruistic behavior contributes to construction of implicit moral education mechanism. Therefore, internet altruistic behavior promotes construction of internet ecological civilization. [8]. Thus researching Internet altruistic behavior of current college students and its underlying reasons is of great significance.

Interpersonal relationship refers to the perceptible and stable psychological relationship shaped by interaction with other people. Interpersonal relations definitely affect individual's behavior. However, strength of the influence depends on the significance of interpersonal relationships as well as individual's own characteristics [9]. Numerous studies have shown that there is a clear correlation between interpersonal relationship and online altruism [10]. Among college students, interpersonal relationship between teachers and students is closely related to the implementation of 
Internet altruistic behaviors [11].

Empathy refers to emotional resonance induced by similar experience with others in the community. That is to say, empathy is the psychological process that a social individual takes the perspective of others, understands others' feelings, and shares similar emotional experience [12]. Researchers also believed that empathy was psychological resonance elicited by a state of mind or a kind of emotion that individuals obtain from similar experience or simple reasoning [13]. During the evolution of human society, empathy plays an extremely critical role, especially in the aspects of social morality, interpersonal relationship, and altruistic behavior [14]. According to the findings of $\mathrm{Li}, \mathrm{Li}$, Shen and Dan [15], basic motivation for Internet altruistic behavior is empathy. For the role of empathy, other scholars believed that one of the motivations of altruistic behavior is empathy [16]. The research in economic interactions conducted by Klimecki, Mayer, Jusyte, Scheeff, and Schönenberg [17] found that, the increase in experienced empathy predicted over $40 \%$ of the increase in sharing behavior. In online environment, social support of individual exists as partial mediation variable and partial regulated variable in the relationship between level of empathy and altruistic behavior [18].

Online social support refers to the degree to which social individuals were identified and supported by others in the Internet [19]. Research by Scarpa and Haden [20] showed that the more social support individuals get online, the more altruistic behaviors and the less hostile and aggressive behavior generated. Yang, Liu and Zhou [21] showed that online social support could significantly account for altruistic behavior in the Internet. Liu, Safin, Yang, and Luhmann's data [22] revealed that an alternative expectation-based mechanism by which social interaction may influence altruistic behavior. Results from Liu, Xu, Liu, and Liu [23] suggested that online social support positively predicted online altruistic behavior. Furthermore, online social support partially mediated between Internet altruistic behavior and subjective well-being [24].

Studies showed that there was obvious correlation between college students' empathy level and their interpersonal relationship. In the process of social relationships, the higher the empathy level, the less anxiety and tension [25]. Among middle school students, interpersonal relationship is significantly correlated with imagination and personal suffering [26]. In turn, the level of physical and mental well-being significantly and positively predicted interpersonal relationship, and compassion and concern significantly and negatively predicted interpersonal relationship [27]. According to the research, in the Internet environment, empathy mainly affected social behavior through the Internet's pro-social motivations [28]. At the same time, Qin [29] pointed out that the individual's empathy level greatly influences the quality of interpersonal relationship. From the perspective of cognitive neuroscience, Balconi and Me [30] examined the differences in empathy during positive and negative interpersonal interaction respectively. Brain imaging results showed that negative interpersonal interaction scenarios activated the right prefrontal cortex, and positive interpersonal interaction under induced activation in the left prefrontal cortex. This study proved the importance of empathy in human interaction from the perspective of neurophysiology.

To sum up, current research mostly focused on interpersonal relationship, empathy, online social support and online altruism. Thus two intermediary models are proposed. The hypotheses are as following:

Hypothesis 1: Individuals' interpersonal relationship and level of empathy can predict online altruistic behavior positively.

Hypothesis 2: The effect of interpersonal relationship in reality on online altruistic behavior is mediated by empathy level.

Hypothesis 3: The effect of empathy on online altruistic behavior is mediated by online social support.

\section{Methods}

\subsection{Participants}

524 students from three universities were investigated on Star Platform, and 196 of which were invalid by their response time was less than 200 seconds. Overall, there were a total of 328 valid questionnaires. The participants included 180 females and 148 males, and $91.46 \%$ of them were 18 to 30 years old. Participants with bachelor's degree, master's degree, and doctoral degree were 212,108 , and 8 respectively. 187 participants came from urban area, and 141 from rural areas. In addition to course credit, participants also received a cash reward ( $¥ 1$ for everyone) after finishing questionnaire.

\subsection{Tools}

\subsubsection{Comprehensive Diagnostic Scale of Interpersonal Relations (CDSIR)}

Established by Zheng [31] in 1999, CDSIR has a total of 28 questions. There were four dimensions, including conversation, friends making and dating, interpersonal, and heterosexual contact. All of the questions were single choice with only a "yes" or "no" option. A "yes" was a score as 1 . A "no" score was 0 . The higher the score, the higher the degree of interpersonal disturbance. The lower the score, the better the interpersonal relationship. In this study, the Cronbach $\alpha$ coefficient was 0.805 .

\subsubsection{College Students' Altruistic Behavior Online Scale}

It was established by Zheng [32] in the year of 2010. It compiled a total of 26 questions. There are four dimensions, including online support, online guidance, online sharing behavior and online notice. It is on Likert scale of 4. Higher score means more online altruistic behaviors. In this study, the Cronbach $\alpha$ coefficient was 0.954 .

\subsubsection{Interpersonal Reactivity Index-C}

It was revised by Zhan [33] based on Davis' (1980) Interpersonal Reactivity Index - C (IRI. C). It compiled a total of 22 questions. There are four dimensions, including 
perspective taking, imagination, the level of compassion and concern, and the level of personal pain. It is on Likert scale of 5. The higher the score, the higher level of empathy. In this study, the Cronbach $\alpha$ coefficient was 0.651 .

\subsubsection{College Students' Online Social Support Scale}

It was established by Liang and Wei [34] in the year of 2008. It compiled a total of 23 questions. There are four dimensions, including support of emotion, information, tool and social member. It was four points scored. The higher the score, the higher level of online social support. In this study, the Cronbach $\alpha$ coefficient was 0.886 .

\subsection{Data Processing}

SPSS18.0 was used to make descriptive statistics and correlation analysis. AMOS22.0 was adopted to establish the structural equation model.

\section{Results}

\subsection{Common Method Bias Test}

Table 1. The matrix table of the mean, standard deviation and correlation coefficient of each variable.

\begin{tabular}{llllll}
\hline Variable & $\boldsymbol{M}$ & $\boldsymbol{S}$ & $\mathbf{1}$ & $\mathbf{2}$ & $\mathbf{4}$ \\
\hline 1 Interpersonal Disturbance & 0.32 & 0.17 & 1.00 & & \\
2 Empathy & 0.33 & 0.33 & $0.14 *$ & -0.10 & $0.31^{* *}$ \\
3Online Social Support & 0.42 & 0.42 & -0.11 & $0.25^{* *}$ & $0.70^{* *}$ \\
4Online Altruistic Behavior & 0.56 & 0.56 & 1.00 & \\
\hline
\end{tabular}

Note: *means $p<.05, * *$ means $p<.01, * * *$ means $p<.001$, the same as following.

\subsection{Mediating Effect Test}

In order to test the mediating effect of empathy and online social support, the relationship of four variables was tested by model of latent variable structure equation model. The latent variable contains multiple observations. There were two mediation models. The first was built by interpersonal relationship, empathy, and Internet altruistic behavior. The second was built by the empathy, online social support and Internet altruistic behavior. The fitting index of the two models was shown in Table 2. The indirect effect of the path
Common method bias is due to the same data source or the rater, the same measurement environment or the same project context, or the artificial covariation caused by the predicted variables and calibration variables with the characteristics of the project. This kind of covariation was a systematic error, which could cause serious interference in the research results [30]. According to the single factor test of Hurman [30], the result of data fitting index made by structural equation model analysis was that $\chi 2 / d f=2.319$, NFI $=0.897$, CFI $=0.938$, RMSEA $=0.064$, which showed that this study does not include serious common method bias.

\subsection{Common Method Bias Test}

As shown in Table 1, interpersonal relationship had significant positive correlation with Internet altruistic behavior and empathy; empathy was significantly and positively correlated with online social support and altruistic behavior; online social support was significantly and positively related to online altruistic behavior. Therefore these results supported hypothesis 1 .

Table 3. The indirect effect size of each path in each model.

\begin{tabular}{lllll}
\hline & \multirow{2}{*}{ The effect size } & \multicolumn{3}{l}{ Confidence interval (95\%) } \\
\cline { 3 - 5 } & & LL95\% & UL95\% & Boot SE \\
\hline Interpersonal Disturbance-Empathy- Online Altruistic Behavior & -0.37 & -1.27 & -0.15 & 0.29 \\
Empathy-Online Social Support - Online Altruistic Behavior & 0.25 & 0.25 & 0.76 & 0.12 \\
\hline
\end{tabular}

In order to reduce model errors as much as possible, Bootstrap calculation was used in the research process [37]. The sample size was set to 5000, and confidence interval was set to $95 \%$. In this condition, researchers thought that if the range of confidence interval does not include 0 , there would was shown in Table 3.

Table 2. The fitting index of the two models.

\begin{tabular}{lllllll}
\hline Model & $\chi \boldsymbol{\chi} 2 / \boldsymbol{d} \boldsymbol{f}$ & GFI & NFI & IFI & CFI & RMSEA \\
\hline Model1 & 1.96 & 0.95 & 0.93 & 0.97 & 0.97 & 0.05 \\
Mode2 & 2.98 & 0.93 & 0.92 & 0.94 & 0.94 & 0.08 \\
\hline
\end{tabular}

According to the opinion of Hou, Wen and Cheng [36], the good standard of fitting index of model was that $\chi 2 / d f<5$, RMSEA $<0.08$, and GFI, NFI, IFI, CFI all $>9$. be a significant effect. As shown in Table 3, the mediating effect of empathy in interpersonal relationship and online altruistic behavior was significant, so as the effect of online social support to empathy and online altruism. The result supported hypothesis 2 and 3. 


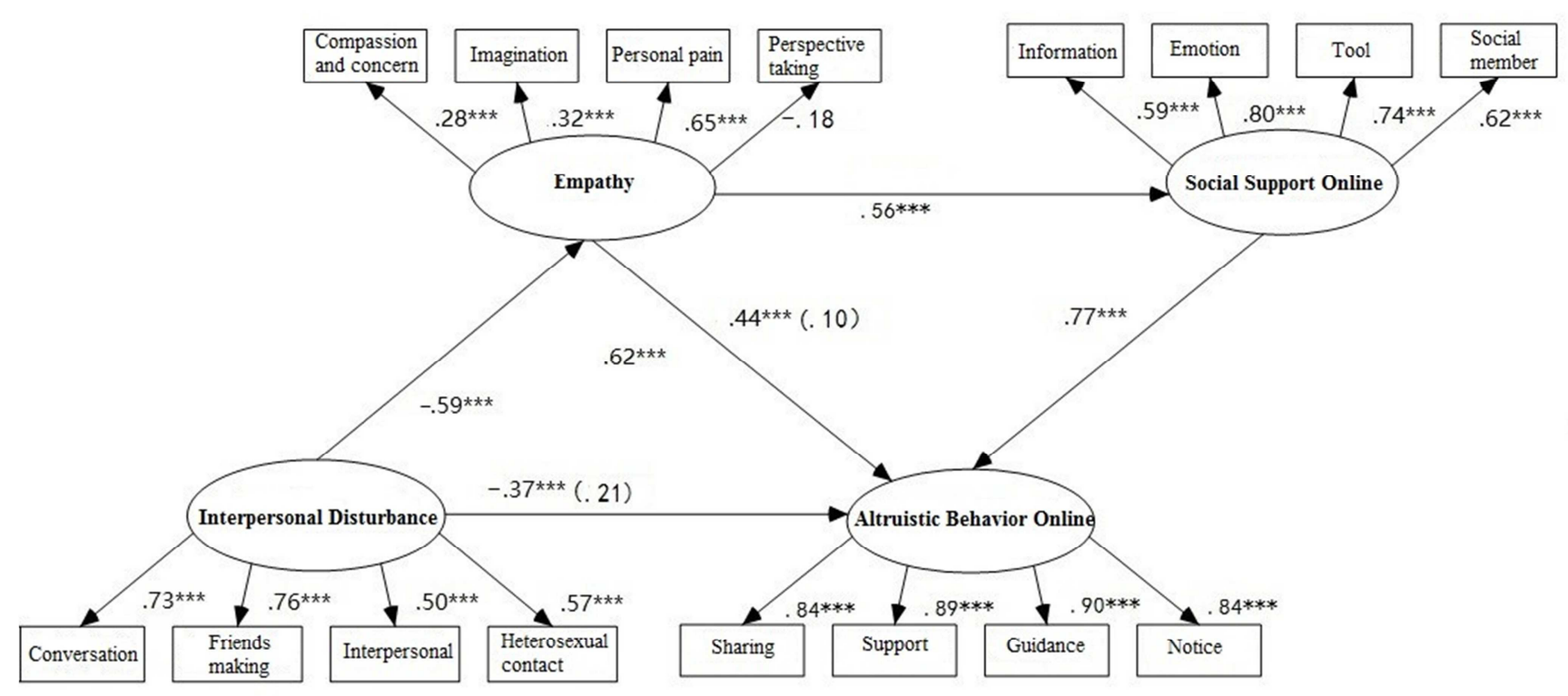

(Note: The value in brackets was the direct effect path coefficient)

Figure 1. The relational model diagram of Interpersonal relationship, empathy, online social support and online altruistic behavior.

From Figure 1, it could be seen that in Model 1, interpersonal relationship disturbance had no significant direct effect on online altruistic behavior, but there was a significant negative effect on empathy. At the same time, empathy had significantly and positively effect on online altruistic behavior. This showed that empathy was a complete mediating variable of interpersonal relationship disturbance and online altruistic behavior. In model 2, empathy had no significant direct effect on online altruism, but it was a significantly positive predictor of online social support. At the same time, the association of online social support and online altruistic behavior was significant positive. This means that online social support played a full mediating role in the association of empathy with online altruistic behavior.

\section{Discussion}

\subsection{Present Situation of Online Altruism in College Students}

According to China Youth Internet Behavior Research Report issued by China Internet Network Information Center (CNNIC) in 2015, young Internet users under the age of 25 in China had reached 287 million, and $48.1 \%$ of them were 19 24 years old. The report also showed that college students Internet users spent 31.7 hours surfing on the Internet weekly. According to the39th Report of Chinese Internet State of Development published by CNNIC on January 22, 2017, there were 731 million Internet users in China as of December of 2016, among which $32.5 \%$ of Chinese Internet users had charity behavior.

The results of this research showed that college students' online altruistic behavior in China was mainly embodied in the aspect of online support $(2.29 \pm 0.59)$, followed by sharing online behavior $(2.10 \pm 0.60)$, online notice $(2.07 \pm 0.65)$, the last was online guidance $(1.95 \pm 0$. 62). The male students exhibit more behavior in online guidance and online notice $(t$ $=2.09, d f=326, p<0.05, \mathrm{~d}=0.23 ; t=2.91, d f=326, p<0.01, d$ $=.32$ ). Compared with female students, this may be because male students mastered more Internet technology, and they would provide more guidance or advice for Internet users. Besides, compared to male students, female students had less advantage in information technology, therefore, when the real problems occurred, individuals may be more likely to turn to male students for help [38]. This was the same result as the research of Liu, Chen, and Zhou [39], internet use was positively correlated with internet use self-efficacy and online altruistic behavior; the mediating effect of internet use self-efficacy was moderated by gender, and this mediating effect was stronger for males than that for female.

\subsection{The Relationship Between Interpersonal Relationship and Online Altruistic Behavior}

Results of this study showed that college students' interpersonal relationship was good overall (8.90土4.73). Interpersonal relationship was significantly and positively correlated with online altruistic behavior. Results of structural equation model showed that interpersonal relationship was significantly and positively associated with online altruistic behavior. According to research of Bucher, Fieseler and Lutz [40], individual's sociability could predict Internet sharing motivation, and the motivation of social sharing was the most powerful predictors of Internet media sharing. Thus interpersonal relationships would influence individual's choice online and offline. The better the interpersonal relationship, the more conducive to individual's online interactive communication with people and the more likely to help others; on the contrary, the greater the interpersonal 
disturbance was, the more possible the individual prefers to be isolated or independent, and the less cooperation with others in the internet.

\subsection{The Mediating Effect of Empathy}

This study found that empathy not only was a completely mediating variable of interpersonal relationship in real life and online altruistic behavior, but also could influence online altruistic behavior through online social support. This was perhaps because individuals with high level of empathy had strong perspective-taking ability. In the world of internet, individual's behavior was less affected by the bystander. So individuals can understand others' situation better, and help others or be a friendly advice provider. Lee [41] pointed out implementers are more likely to help help-seekers when they could understand the them better and when they were free to choose to do it or not. By chance, internet meets this condition. This results showed that, compared to male students, female students' level of empathy was higher $(t=2.62, d f=326, p<0$. $01, d=0.29$ ), especially on the dimension of the level of personal pain and perspective taking $(t=3.30, d f=326, p<0$. $001, d=0.37 ; t=-5.50, d f=326, p<0.001, d=0.61)$. From the perspective of evolutionary psychology, females may be more sensitive to the situation of others and are more likely to help others due to their innate maternal traits.

\subsection{Intermediary Role of Online Social Support}

Based on the investigation of 110 open source project contributors, working in open source projects was primarily motivated by a sense of altruism. One of the most important motivating factors was contributors' desire to make more contribution throughout the world, because they enjoyed the software, tools and knowledge shared by others in the internet [42]. This conclusion was consistent with results of this study. Online Social support (internal psychological process) acts as the mediating role of empathy and online altruistic behavior (external actual behavior), which could translate empathy into actual behavior effectively. Encouraged by social support online, individuals are more likely to show empathy and display altruistic behavior effectively [38]. In the internet environment, online social support could promote the groups in need of social support to have more opportunities for interpersonal interaction [43]. Indirectly, it could promote Internet altruistic behavior. In addition, according to learning theory, individuals had the advantage of learning social norms from other members of the society. Openness of the internet environment provided the Internet users with more opportunities to learn from others. Altruistic behavior became a very important part of learning. Internet provided information, emotion regulation, tools, and social support.

\subsection{Implications and Limitations of This Study}

Based on interpersonal relationship, this study explored the influence mechanism of two intermediary models on online altruistic behavior and enriched the existing research. Rresults revealed that online altruistic behavior was influenced by interpersonal relationship, empathy and social support etc. From a practical point of view, cultivating individuals to form a good interpersonal relationship and ascending individuals' level of empathy were conducive to increasing online altruistic behavior. From the perspective of Internet, the information provided by online platform and resource supported from offline to online were also conducive to the increase of online altruism. In this age when almost everything could be found online, trend of individual's help-seeking behavior had been transferred from offline to online gradually. Thus, in order to strengthen the construction of online platform, and to build a harmonious online environment, it was helpful to promote development of interpersonal relationship and level of empathy.

However, this study was cross-sectional. It didn't make in-depth discussion of relationship of interpersonal relationship and online social support. It did not form a complete sequence of intermediary effect. Other factors that affect Internet altruistic behavior remain to be further researched in future. Therefore, it is necessary to extend study to populations other than college students, or to use longitudinal studies to explore a deeper causal relationship between these variables.

\section{Conclusion}

This study examined relationship among interpersonal relationship, level of empathy in a just world, online social support, and online altruistic behavior in a sample of Chinese college students. Interpersonal relationship and level of empathy can predict online altruistic behavior positively; the effect of interpersonal relationship in reality on online altruistic behavior is mediated by empathy level; the effect of empathy on online altruistic behavior is mediated by online social support. It is helpful for researchers and policy-makers to work on measures to improve college students' subjective well-being and to promote the network ecological civilization construction by increasing their internet altruistic behavior.

\section{References}

[1] Gosling, S. D., \&Mason, W. (2015). Internet research in psychology. Annual Review of Psychology, 66, 1-26.

[2] Killian, M., Fahy, J., \&O’Loughlin, D. (2016). The Case for Altruism in eWoM Motivations. Making a difference through marketing. Springer Singapore.

[3] Xiao, F, Q., Zheng, Z, W. \& Chen, Y, H. (2014). Neural Basis and Effects of Empathy on Prosocial Behaviors. Psychological development and education. 30 (2), 208-215.

[4] Zheng, X, L. (2013). The theory and empirical study of online altruism. Beijing: Chinese social sciences press.

[5] Zheng, X., \& Wang, Y. (2017). The relationship between internet altruistic behavior and subjective well-being among adolescents: a mediated moderation model. Journal of Psychological Science. 
[6] Liang, Q, S. (2017). Study on the network altruistic behavior of adolescents from the perspective of positive psychology. Theory and Practice of Education. 23 (37), 24-26.

[7] Wang, P, C., Wu, G, F., \& Yao, Q. (2017). Current Status Analysis of Internet Altruistic Behavior with the Perspective of Internet. Journal of Anhui University of Science and Technology (Social Science). 3 (19), 28-31.

[8] Wang, Z, Q., \& Wang, Y. (2015). Internet altruistic behavior and network ecological civilization construction. Journal of Shanxi Normal University (Social Science Edition), 4 (42). 69-72.

[9] Li, X, D., Nie, Y, Y. \& Lin, C, D. (2012). The Effects of Learning Difficulty, Interpersonal Relationship and Self-Acceptance on Eighth Grader' mental Health. Psychological development and education. 2, 68-73.

[10] Liu, H., Huang, X., Du, B., \&Wu, P. (2014). Correlation study on undergraduates' Internet altruistic behavior, self-concept and inter-personal relation. Advances in Applied Sociology, 04 (4), 128-133.

[11] Liu, H, Y. \& Huang, X, K. (2014). The characteristics of online altruistic behavior of college students and related fators. Education of Henan province. (9), 95-96.

[12] Hogan, R. (1969). Development of an Empathy Scale. Journal of Consulting and Clinieal, 11 (33): 307-310.

[13] Jackson, P. L., Meltzoff, A. N., \&Decety, J. (2005). How do we perceive the pain of others? A window into the neural processes involved in empathy. Neuroimage, 24, 771-779.

[14] Li, X, H. (2012). The Relationship of College Students' Empathy, Personality and Interpersonal Relationship. Master's Thesis. Harbin normal university.

[15] Li, W, H., Li, C., Shen, Y. \& Dan, F. (2015). Effect of Empathy on College Students' Altruistic Behavior: A Mederated Mediation Model. Psychological development and education. 31 (5), 571-577.

[16] Pan, Y, G., Liu, Y, L., Ran, G, M., Lei, H., Ma, S. \& Teng, Zhao, J. (2013). Altruistic Nature of Animal and Human: The Evolution of Empathy. Advances in Psychology, 21 (7), 1229-1238.

[17] Klimecki, O. M., Mayer, S. V., Jusyte, A., Scheeff, J., \& Schönenberg, M. (2016). Empathy promotes altruistic behavior in economic interactions. Scientific Reports, 6, 31961.

[18] Jiang, H, B., Zheng, W, L., Ma, S., Xiao, W, L. \& Zhang, B. (2016). The relationship between altruism online, empathy and social support in college students. Journal of Shandong normal university, 31 (3)132-138.

[19] Turner, J. W., GrubeA., \&Meyers, J. (2001). Developing an optimal match within online communities: An exploration of CMC support communities and traditional support. Journal of Communication, 55, 231-251.

[20] Scarpa, A., \&Haden, S. C. (2006). Community violence victimization and aggressive behavior: The moderating effects of coping and social support. Aggressive Behavior, 32 (5), 502 -515.

[21] Yang, X, X., Liu, Q, X., \& Zhou, Z, K. (2017). The influence of online social support on online altruism: gratitude and social identification. Psychological development and education. 33 (2), 183-190.
[22] Liu, P. P., Safin, V., Yang, B., \& Luhmann, C. C. (2015). Direct and indirect influence of altruistic behavior in a social network. Plos One, 10 (10), e0140357.

[23] Liu, Q, W., Xu, Q, C., Liu, H, S., \& Liu, Q, X. (2016). The Relationship between Online Social Support and Online Altruistic Behavior of College Students: A Moderated Mediating Model. Psychological Development and Education. 32 (4), 426-434.

[24] Zheng, X, L., Ding, L., \&Yuan, Q, X. (2017). The Effect of Internet Altruistic Behavior on Adolescents' Subjective Well-Being: The Moderated Mediation. Chinese Journal of Special Education, 8 (206). 80-87.

[25] Chen, X., Zhang, X, W. (2012). To Improve the Interpersonal Competence of Undergraduates by Empathy Training. Journal of Xinjiang University. 40 (6), 41-43.

[26] Kou, J., Liu, Y., Song, H. \& Zou, Z, L. (2015). The Correlation Research on Empathy and Interpersonal Relationship among Senior Middle School Students. Advances in Psychology, 05, 134-141.

[27] Zhai, S, J., Zheng, S, J., Wang, L, Y., \& Quan, Z, W. (2011). The characteristics and relationship of college students' empathy and interpersonal relationship. Journal of Changsha normal college (2), 53-57.

[28] Chen, S, S. (2015). Influencing factors of college students' network social behavior. Master's Thesis. Beijing Forestry University.

[29] Qin, Z, Y. (2016). The relationship between students' empathy and interpersonal relationship. Shanxi Youth (14).

[30] Balconi, M., \& Me, M. E. V. (2017). Empathy in negative and positive interpersonal interactions. What is the relationship between central (EEG, fNIRS) and peripheral (autonomic) neurophysiological responses? Advances in Cognitive Psychology, 13 (1), 105-120.

[31] Zheng, R, C. (1999). Psychological diagnosis of college students. Jinan: Shan Dong education press.

[32] Zheng, X, L. (2010). Online altruistic behavior of college students: scale production and multi-level linear analysis. Shanghai normal university Doctoral dissertation.

[33] Zhan, Z, Y. (1996). The relationship of grade, gender role, human orientation and empathy. Education institute of Taiwan university political university, 125-154.

[34] Liang, X, Y., \& Wei, L. (2008). A Preliminary Study of College Students' Online Social Support Testing. Psychological science, 31 (3), 689-691.

[35] Zhou, H., Long, L, R. (2004). Statistical Remedies for Common Method Biases. Advances in Psychology, 12 (6), 942-950.

[36] Hou, J, T., Wen, Z, L., \& Chen, Z, J. (2004). Structural equation model and its application. Education science press.

[37] Preacher, K, J., Rucker, D. D., \&Hayes, A. F. (2007). Addressing moderated mediation hypotheses: theory, methods, and prescriptions. Multivariate Behavioral Research, 42 (1), 185-227.

[38] Zhao, H, H., Zhang, H, Y., Liu, Q, X., Wang, F, X., \& Zhou, Z, K. (2012). College Students' Trait Empathy and Internet Altruistic Behavior: The Mediating Effects of Online Social Support. Psychological development and education. 28 (5), 478-486. 
[39] Liu, Q., Chen, W., \& Zhou, Z. (2015). Internet use and online altruistic behavior in college students: the role of internet use self-efficacy and gender. Psychological Development \& Education.

[40] Bucher, E., Fieseler, C., \&Lutz, C. (2016). What's mine is yours (for anominal fee) - exploring the spectrum of utilit ariantoaltruisticmotives for Internet-mediated sharing. Computers in Human Behavior, 62 (C), 316- 326.

[41] Lee, G., \&Lee, W. J. (2010). Altruistic traits and organizational conditions in helping online. Computers in Human Behavior, 26 (6), 1574-1580.

[42] Baytiyeh, H., \&Pfaffman, J. (2010). Open source software: a community of altruists. Computers in Human Behavior, 26 (6), $1345-1354$.

[43] Kraut, R., Kiesler, S., Boneva, B., Cummings, J., Helgeson, V., $\&$ Crawford, A. (2002). Internet paradox revisited. Journal of Social Issues, 58 (1), 49-74. 